\title{
Genomic Instability in Cancer I: DNA-Repair Triggering Primitive Hereditary 4n-Skewed, Amitotic Division-System, the Culprit in EMT/MET/Metaplasia Cancer-Concepts
}

\author{
Kirsten H. Walen \\ Cromos, Richmond, CA, USA \\ Email: kwalencromos@gmail.com
}

How to cite this paper: Walen, K.H. (2018) Genomic Instability in Cancer I: DNA-Repair Triggering Primitive Hereditary $4 \mathrm{n}$-Skewed, Amitotic Division-System, the Culprit in EMT/MET/Metaplasia Cancer-Concepts. Journal of Cancer Therapy, 9, 974-997.

https://doi.org/10.4236/jct.2018.912081

Received: October 18, 2018

Accepted: December 10, 2018

Published: December 13, 2018

Copyright $\odot 2018$ by author and Scientific Research Publishing Inc. This work is licensed under the Creative Commons Attribution International License (CC BY 4.0).

http://creativecommons.org/licenses/by/4.0/

\section{Open Access}

\begin{abstract}
The objective was to gain proof of genome damage-repair induced mitotic slippage process (MSP) to $4 \mathrm{n}$-diplochromosome skewed division-system, earlier suggested to have "cancer-deciding" consequences. Our damage-model showed two succeeding phases: molecular mutations for initiation of fitness-gained cells, and large chromosomal changes to aneuploidy from inherited DNA-breakage-repair inaccuracies. The mutations were gained while DNA-repair and DNA-replication, co-existed in the route to tetraploidy, a phenomenon also expressed for some existing unicellular organisms. These organisms also showed genome reductive, amitotic, meioticlike division, and was the origin of human genome conserved, self-inflicted $90^{\circ}$ reorientation of the $4 \mathrm{n}$ nucleus relative to the cytoskeleton axis. In the in vitro DNA-damage model, this remarkable $4 \mathrm{n}$-event deciding "flat-upright" cell-growth characteristics showed several consequences, for example, cancer-important, E-cadherin- $\beta$-catenin cell-to-cell adherence destruction, which gave diploid progeny cells, mobility freedom from cell contact inhibition, likely in renewal tissues. This $4 \mathrm{n}$-skewed division-system with inheritance in progeny cells for repeat occurrences as mentioned for flat-up-right growth patterns is similar to claimed concepts of metaplasia-EMT/MET embryogenesis events in cancer evolution. A scrutiny of this literature, proof-wise invalidated this embryological concept by tetraploid $8 \mathrm{C}$ cells occurring in MET events and, was noted for small cell occurrence, i.e., diploidy from $4 \mathrm{n}-8 \mathrm{C}$ reductive division, an also event for tumor relapse cells, derived from genome damaging therapy agents. Pre-cancer hyperplasia reported MSP, cadherincatenin destruction and $90^{\circ}$ perpendicularity to basal cell membrane. The DNA-damage-repair model can weed-out therapy-agents triggering $4 \mathrm{n}$-skewed division. Cancer-control, be-
\end{abstract}


ginning-information, is likely from mutational identity of the $4 \mathrm{n}$ derived fitness-gained cells.

\section{Keywords}

Cancer Evolution, DNA-Damage-Repair, Mitotic Slippage, Hereditary

Primitive Tetraploidy, $90^{\circ}$ Amitotic Skewed Division, Fitness-Gain,

Embryogenesis-Type EMT/MET, Human Cell Conservation

\section{Introduction}

Have we made cancer disease into a mysterious, complex issue much more than it really is, if so, why? The "big picture", if staying within scientific reasons (aside from commercial interest), is that too much faith has been placed on cancer cell, molecular sequencing for mutational know-ledge, being the definitive answer to a solution of the cancer-riddle [1] [2]. Now 30+ years later, there is an immense quantity of difficult to interpret mutational data, showing various types of molecular nucleotide lesions [1] [3]. This overall "unsolvable" data has even led to the suggestion of needed mathematics for the understanding of tumorigenesis [4], which is actually occurring [5] [6] [7]. These theoretical models of tumorigenesis have included second generation sequencing results, but these finer and finer dissections of the cancer genomes, have only led us further away from biological thinking. So far away that the reality of biological, mitotic, cause of mutations do not exists in the minds of "reigning" cancer-chemists. Integration from their mutation data, specific mutations in faulty mitosis for potential mitotic-targeted therapy, is impossible. But life goes on with schools teaching cancer biology as cancer chemistry, completely ridding this job-market of biology thinking also needed from another perspective of cancer development, the huge data-bank on karyotype aneuploidy [8] [9]. All in all, the now, massive available data on cancer development is a complex mess with "trees not being seen for the forest”, more precisely expressed by cancer-investigation lacking a paradigm [10]. Thus, if a decision is made that the first goal/paradigm is to investigate cancer-beginning/initiation, which is an agreed-upon feature of gain in fitness of a normal human cell [11] [12], then the cancer relevant literature becomes considerably shrunk. If a further weeding excludes carcinogen/viral experiments, which are not happenings for sporadic cancers, and a further elimination is done for ideas of initiation, deducted from cancer cell line-experiments, then there are only a few qualifying sources left. This latter dismissal (not effecting "progression" literature) is necessary, because such cancer cells are already positive for activated telomerase gene, associated with immortality, which normal human cells must gain. These gains however, have yet to be shown evidentially, directly from "disturbed" normal human cells, although claimed. The observations of benign pre-cancer diploid, cell-proliferation (hyperplastic), preceding a senescent arrest, associated with oncogenic transformation to immortality cells, will 
be the accepted route herein. Another agreed-upon cancer occurrence is that cancer is a multistep process [10] [13], known as initiation and progression to malignancy [14]. Somewhat debated is the suggestion of chromosomal instability (CIN) and/or a mutator mechanism in this multiyear evolution to malignancy [15].

\section{Cancer Pathology in Sense-Making of Cancer Literature}

As mentioned, in cancer pathology the first "warning" phenotype is pre-cancers with hyperplastic cell proliferation, which are cells having gained a proliferative advantage (fitness-gain), and with origin from normal human cells. This occurrence leads back to the question of how normal cells in renewal tissues where cancers originate, gained this fitness increase? The literature has many suggestions, but zeroing in on those from normal human cells, the most likely occurrence from a genetic point of view is tetraploidy with asymmetric chromosome segregation to chromosome altered (aneuploidy) progeny cells. Experiments with induced endoreplication to $4 \mathrm{n}$ cells, did not show the desired result, but instead the $4 \mathrm{n}$ cells became division-arrested, being referred to as the tetraploid paradox [16] [17] [18]. Contrary to these results we found that another type of tetraploidy from DNA-repair induced mitotic slippage process (MSP) with re-replication of diploid cells, giving rise to tetraploid cells, but with 4-chromatid chromosomes (diplochromosomes), divided without any arrest-disturbances (absence of mitotic checkpoints). These orderly divisions were of course, different from mitosis/meiosis, because of chromosome structure, but were meiotic-like in that the chromosome segregation process was genome reductive to karyotype normal diploid cells [19] [20] [21]. The diploid progeny cells unexpectedly showed gained "generational" fitness-increase, meaning dilutions were necessary for cell culture passage from the first proliferative-burst in 25-T-flasks. The normal karyotype suggests fitness-gain from molecular mutations, which is in agreement with very limited tolerance of aneuploidy of normal human cells [22]. This in vitro machinery, is herein evaluated for causation of pre-cancer hyperplasia, and is "dissected" for tumorigenic "single chain of causality" [15] which provided unanticipated answer to assumed, embryological metaplasia-EMT/MET in cancer evolution.

\section{The Development of a New-Look Mutation Theory}

Accepting that the goal for tumor initiation is gain of fitness in normal human cells, the mutation data from tumor sequencing demonstrated that certain gene-specific, mutations occurred more frequently than others, i.e., mountains versus hills [10] [23]. The mountain mutations were considered to be cancer causative with tumor driver capacity, and the hill mutations, were named passengers without driver capacity. The driver mutations have become the focal issue in immunotherapy in which, some 50 of them, in proprietary secrecy, are being tested for antibody-T-cell production against the tumor cells [24] [25]. At 
this time there has been some extraordinary cure-treatments, and many more are hoped-for, but awaiting FDA approval for patient-use. But, there are also varied results, suggested to come from patient, specific immune-response, or from other problems, adding "missing-links" for this invaluable approach to cancer-therapy. These driver, mutated genes, called cancer-genes (CAN-genes), and cells carrying them being "tumor initiating cells" (TICs) [26], appear to need re-evaluations from original articles, describing them [10] [23], and also from a later description [27]. It is clearly expressed that today believed characteristics of these CAN-gene-mutations were from interpreted functions awarded to them in the carcinogenic process. Thus, tumor driver capacity dealt to the mountain mutations has no real. factual evidence, it was explained as follows: "This new view of cancer is consistent with the (note) idea that a large number of mutations, each associated with a small fitness advantage, drive tumor progression". Moreover: "Driver mutations are causally involved in the neo-plastic process and are positively selected for during tumorigenesis" [23]. The predicted fitness increase of the driver mutations, was calculated from a tumorigenic model, and shown to be "surprisingly low" (0.4\%) [10]. The authors themselves, pointed out that experimental proof in cell culture for fitness increase, was prohibited. Of note (see below), in addition to these CAN-gene mutations being in structural genes there was identification of molecular "mutations" (deficiencies) twice as frequent in noncoding DNA, which is a repair unsolved issue, not mentioned in MT [10] [23], and neither in a rather, succinctly described "cancer genome" [7] [28]. Unsolved is also whether mutations can be caused by a mutator mechanism [29] [30] [31], and/or by CIN [32]. But the critical question is whether the "awarded" CAN-gene mutational characteristics are deserving of todays, central role they have in immunotherapy [24] [25]. Noteworthy, is the absence of cancer eradication, a promise some years ago, which we think can be achieved by vaccine development [33] from our herein, focused approach to biomarkers of initiation.

\section{A Cellular Mechanism in Cancer Initiation and Evolution}

To this "mountain/hill" mutation data, there is also a huge data-bank on abnormal karyotypes from both solid and hematological cancers, which also has been unyielding to interpretation(s) of their origins [34] [35] [36]. In 1987, some 9000 cancer-cases had been karyotyped with some results, especially baffling, defying any type of explanation, as for example, that specific chromosomes were more often involved in aberrations than others [37] [38]. But, most peculiar was that different patients could present with same type of primary, karyotype abnormality, per-haps suggestive of a repeatable event in normal cells, which was difficult to assign to a specific mutation according to the MT. Instead, a repeatable cellular event, causing aneuploidy with specificity in renewal tissues from micro-environmental selection, appears more likely. For this to occur we suggest the mentioned $4 \mathrm{n}$-skewed division-system, having from known inducer system 
and detailed chromosomal analyses, shown integrity in repeatability and, in production of fitness increased cells from normal human cells.

1) Normal human cells going through MSP, giving rise to special diplochromosome tetraploid

From a series of experiments with normal human cell strains near senescence with unstable double strand, broken (DSBs) telomeres, tetraploid diplochromosomal (4 chromatids) cells were observed [20] [21], capable of division without arrest from cell cycle checkpoint control [39] [40]. The telomeric DSBs had long since been a subject matter in studies of non-homologous end-joining [41], and the specific diplochromosome tetraploidy at this DSB-senescent stage was verified some years later [42]. These observations gave the idea of DNA-DSB-repair being the origin to chromosomes with 4 chromatids, and with described tetraploidy from mitotic slippage process (MSP) [43], two and two made four: DSB-repair, inducer of MSP cycling to the special tetraploidy. This idea was tested in young normal human cells, made to carry genomic damage by transient exposure to culture medium deficient in amino acid glutamine, previously shown to induce polyploidy, and being a significant metabolic-source for DNA nucleotides [44]. Daily harvests of chamber slide-cultures for in situ analyses, indeed revealed diplochromosomal cells, which surprisingly showed an orderly, division-system to fitness-gained diploid cells. Summarily, the division-system was an amitotic (no spindle apparatus), two-step meiotic-like, first segregation of whole complements, and secondly a simple fission-division of the first division products $(4 \mathrm{n} / 4 \mathrm{C})$, giving rise to the diploid cells [45] [46]. Of note, is that the first division was equational and the second was reductive, which is reverse of meiosis and, with occurrence in hermaphroditic animal species [47]. This event and the number of diplochromosomes being 46, preclude any involvement of meiosis, which should have shown 23 chromosomes from homologous pairing. Whole complement-segregation have been reported in human placental tropho-blasts in the absence of a spindle apparatus, and for "meiotic-like" division of PtK-1 cells, lacking centrioles [48] [49].

2) DNA-double strand breaks repairing during replication process

Genomic damage-repair of DSBs in a cancerous process, is a frequent literature encounter, and only two are mentioned here for special reasons (see below) [50] [51]. For the former see title and reasoning, and for the latter, the $2 \%$ of X-ray induced DSB-repairs was by homologous recombination (HR) between "-non-allelic repetitive elements-", which is a rather unusual repair-mechanism likely involved in cancer-observed chromothripsis [52] [53]. Another feature of DSBs, occurring in S-period of the cell cycle, is that repair-mechanisms can be expressed while the cell continues DNA replication, but with a slowed down speed, which has the consequence of disturbing cell cycle-timing [54]. These peculiarities are mentioned (in prep.), because cell cycle time of $4 \mathrm{n}$, diploid progeny cells, PtK-1 \& 2, was measured from autoradiography of tritiated thymedine incorporation, and found to be about 3 hours shorter than for control, normal marsupial, Potoroo cells (2002 [55]. Autoradiographs of present 
human diplochromosomal cells [56] demonstrated non-randomness in chromatid replication process, and extensive, sister chromatid chiasmata from recombination repair-processes [20], emphasizing "break and repair" in this $4 \mathrm{n}$-situation. Of note, is that reduced cell cycling time is in itself a proliferative advantage, which for the fitness gained $4 \mathrm{n}$-derived diploid cells, may well have been in addition to mutations created by inaccurate repair [57] - the mutator phenotype [30]. Today, the Mayo Clinic (2018 Cure Cancer Drive Letter) acknowledges "DNA strand damage" in tumor development, and has a protein (L3MBTL2) activated in repair (otherwise unknown), which ought to be investigated for links to the $4 \mathrm{n}$-skewed division-system. Repair of DSBs is also known to be associated with conserved, cohesin down-load [58] [59], which no doubt conferred structural stability in re-replication to the 4-chromatid chromosomes, and also secured orderly whole complement segregation. As said (Mayo Clinic letter), molecular discovery of repair- "missing links" may lead to "more effective therapy", which earlier-on was a "given" co-operative situation for cancer-related biology [60]. But, is the "will" and trained scientists there today?

\section{Cell Contact Inhibition of Proliferation: A Tumor Suppressive Mechanism in Renewal Tissues}

Cancer development almost exclusively in renewal tissues must overcome this proliferation prohibiting condition, but barely mentioned as such in cancer research. The variously differentiated tissues prevent unscheduled cell proliferation by a cell-to-cell, patterned architectural structure, determined by several features "gluing" cells to each other [61] [62] [63]. This elaborate, proliferation controlling-system must somehow be glued-dissolved with cells gaining freedom and movability for potential cancer-initiating proliferation. From carcinogenesis studies it was concluded that cancer development was "development gone awry" [64]. This suggestion has had historic support by cancer development in von Hansemann's time, thought to have an embryo-logical origin [65]. But, von Hansemann, a keen microscopist with photography capacity, came to the conclusion that cell-shape changes from epithelioid tissues occurred on a more or less continuing bases with the cancer cell gaining roundness shape, facilitating independent living. This gradual gain of roundness morphology of mature cancer cells however, suggests repeated cytoskeleton axial, cell-polarity changes, necessary for cell division. But change/loss of cell polarity is more or less an absent issue in cancer studies today, the less proven idea of development gone awry, is glibly accepted, and is now fueling an intense search for biomarkers of embryological epithelial cell transition to mesenchymal cells (EMT reverse MET), thought to be operating in cancer evolution [66].

1) Epithelial cell changing to cuboidal cell growth-flat versus upright

The EMT/MET occurrences in embryology are based on one cell-type changing into another, which likely has many effectors [66] [67] [68]. One rather well know example, known from very early tumorigenesis, is effected by disruption of the E-cadherin- $\beta$-catenin linkage [26] [69]. These cell-to-cell adherence pro- 
teins occur in tight junctions between epithelial cells, and has time and again been observed with disruptured function, latterly reported in pre-cancer hyperplasia with causation of skewed cell growth [70] [71]. Interestingly, in cancer evolution, they show a gradual, quantitative decrease with almost absence in the carcinoma phenotype [69]. In normal contact inhibited cells, these proteins are united to form a bridge to the cytoskeleton by E-cadherin being cell-external (causing neighbor cell adherence) with a trans-membrane extension being linked to $\beta$-catenin, which bridges the gap for attachment to the cell polarity axis, the cytoskeleton. Today, this assembly has been described from Hippo signaling pathway [63] [72], and disruptions, from $\beta$-catenin becoming located in the nucleus and not in the normal cytoplasm place (see below) [69]. Such cadherin-catenin functional destruction has been shown to be a basic operational feature in embryological EMT [73], which causes a near basal membrane cell to turn $90^{\circ}$ to the membrane with start of skin thickness growth (upright). In other words the EMT was effected by a perpendicular, whole cell turn, changing the cell polarity to upright with consequent mitoses in this new axial change.

2) In vitro cell-events leading to disruption of cadherin-catenin functionconsequences

Recently, cell contact inhibition of proliferation was concluded to be a question of "spatial constraint" [74], which agree with our finding of a similar situation in cell culture, monolayer contact inhibited cells [75] [76]. Only in small cell islands ( 300 - 500 cells) with somewhat loose, contact between the cells, and not in confluent cultures, were the special $4 \mathrm{n}$ cells (above) observed. These "flakes" of cells had been made to carry genomic damage (amino-acid-AA) glutamine deficiency treated), and showed mitoses only at the peripheries. The occurring $4 \mathrm{n}$ cells could show a peculiar, self-inflicted $90^{\circ}$ nuclear rotation relative to the cytoskeleton axis. Such cells were microscopy followed, and showed the familiar, amitotic division-system in this perpendicular direction relative to the cell cytoskeleton axis. The cytology firstly revealed a pear-shape "mother-cell", which became more flattened from apical and basal cell regions with-drawing from immediate, neighboring normal diploid cells. This continuous division sequence ended with cytokinesis into two more or less flattened progeny cells also in a perpendicular or highly skewed orientation relative to the normal cell surrounding. This peculiar, self-generated $4 \mathrm{n}$ division-sequence had effected a "whole-cell" change from "flat to upright" possibility of cell proliferation. This inescapable conclusion demonstrated fitness gained, diploid cell propagation in a changed direction from original fibroblastic, striated pattern, freed from contact inhibition. Next the question is whether the mother-cell "withdrawal", destroying cadherin-catenin mole-cules, was helped by endocrine secretion and/or kallikreins (metallo-proteinases), early observed tumorigenic events [77]. Nevertheless, the flattened progeny cells would be doomed to build a new cytoskeleton in polarity direction of the nucleus. Strong support for this conclusion, is from aggressive oral cancer cells with the cytoskeletons in a skewed position [78]. And, change/loss of cell polarity, has been suggested to be the "gateway" to 
cancer [79] [80].

3) Does this self-made $4 \mathrm{n}$-cell-sequence occur in vivo contact inhibited renewal tissues?

Of note, is that pre-cancers with hyperplasia from different types of renewal tissues, have been reported to accumulate $4 \mathrm{n} / 4 \mathrm{C} / \mathrm{G} 1$ cells in the diploid hyperplastic cell growth [40] [70] [71] [81] [82]. In the DNA-damage-repair, MSP in vitro model, such $4 \mathrm{n}$ cells were products from first equational division of $4 \mathrm{n} / 8 \mathrm{C} / \mathrm{M}>4 \mathrm{n} / 4 \mathrm{C} / \mathrm{G} 1$, followed by more rarer, reductive fission-division of the $4 \mathrm{n} / 4 \mathrm{C} / \mathrm{G} 1$ cells to the fitness gained diploid cells (see above). In hyperplasia (fitness gained cells) of $\mathrm{BE}, 4 \mathrm{n} / 8 \mathrm{C}$ cells were found to segregate with reductive division to hyperplastic diploid cells [21] [81], and in colon crypt cells with mutated APC gene, MSP was implicated in the production of the $4 \mathrm{n} / 4 \mathrm{C} / \mathrm{G} 1$ accumulating cells [70]. But most importantly, the hyperplastic crypt cells showed, measured, $90^{\circ}$ cell polarity axial change, relative to the basement membrane [70]. Measurements discarded up to $30^{\circ}$-cell-changes as accidental, emphasizing the reality of this peculiar in vivo happening. Furthermore, these crypt cell studies [71], showed destruction of the E-cadherin protein linkage to $\beta$-catenin by the $\beta$-catenin protein being observed in nuclei, and not in the normal cytoplasmic place. These two special observations, are undoubtedly consequences from the extraordinary, $4 \mathrm{n}$-cell, self-inflicted $90^{\circ}$ machinery. The evidences for special $4 \mathrm{n}$-cell division-sequence in initiation of tumorigenesis are becoming unquestionable, especially because the APC mutated crypt cells showed change to $3 n-4 n$ cycling, dysplastic cells, which culminated in the carcinoma phenotype [70] [71] [82] [83]. Only one study has been found, commenting on this cancer causative, chain of events, which acknowledged genome reductive behavior of $4 \mathrm{n}$ cells as a source for the diploid, hyperplastic cells [84]. The cancer-related reality of the $4 \mathrm{n}$ cell division-system with spontaneous $90^{\circ}$ skewed geno-phenotype, is hence, called "4n-skewed division-system", setting it apart from other types of tetraploidy.

\section{How Is DNA-DSBS Created for Spontaneous Tumorigenesis?}

In the above crypt cell experiments with mutated APC gene, an article also published in 2007 reported on mutated APC, causing chromosome damage in normal cells [85]. The truncated, mutated protein from loss of the carboxyl-terminal sequence, needed for proper microtubule interactions, caused mitotic chromosome miss-segregation, anaphase bridges, and bi-nucleated cytokinesis. Abnormal spindle apparatus in anaphase is a known cause of bridge-breakage to DSBs with mentioned B-F-B repair cycles [81] [82] [83] [86] [87] [88]. Moreover, the truncation of the protein with loss of binding sites to other normal proteins, was suggested to affect other normal signaling pathways. The pro and con of these observations in normal human cells, are not unexpected (see 85 for refs), because most of the other data was derived from cancer cell lines and mouse cells. However, a consideration of the normal functions of the APC gene is quite re- 
vealing, and is predictive of the observed mitotic abnormalities from the mutation. The normal protein is first located in the centromere regions, followed by a move to microtubules in mitosis where together with other proteins, normal function of the spindle apparatus is secured. The final move is to the centrosomes, which safeguards normal cytokinesis (Googl). Thus, it is no accident that a high incidence of bi-nucleated cells from centrosome dysfunction was observed in mutated APC crypt cells [71]. This gross chromosome damage effect from mutated APC is in line with other hyperplasia being preceded by genome damaged normal cells, in $\mathrm{BE}$ and ulcerative colitis, respectively from acid reflux disease and bacterial-cell induced damage [81] [82]. Furthermore, mutated APC "discoverers" in colorectal types of cancers, noted that the mutation caused early tetraploidy [38], which is expected from DNA-damage-repair, leading to $4 \mathrm{n}$-skewed, amitotic division-system. All in all, it is becoming more and more difficult to refute the idea of genome-repair, triggering MSP cycling to $4 \mathrm{n}$-skewed division-system, is initiating hyperplastic cells.

\section{Distictions between Initiation and Oncogenic Transformation, i.e., Cells Producing Tumors in Mice}

There is no clear understanding of whether initiation and immortality are one or two processes [89]. And experiments with vector-transfusion of cellular "elements" into human cells, including TERT subunit of the telomerase protein, have not clarified the problem [90] [91]. However, more recently, the TERT-unit was not included, and the cells were normal human, epithelial breast cells [92] [93]. For these normal human cells the early anti-proliferative stasis-phase (senescence-like phase) was avoided by the targeting of tumor suppressive p16 gene (CDKN2A) with shRNA, which prevented raised expression of mutated CDKN2A (p16ink4a), the inducer of the stasis phase. This was followed by MYC oncogene transduction, annulling TP53 protein accumulation for senescence induced stop of proliferation. Thus, cells were kept in a proliferative state, which resulted in non-clonal reactivation of the telomerase gene with associated immortality of diploid proliferative cells, which was different from the expected in vivo happening of trip-tetraploid cell cycling [83]. The authors [92] [93] suggested unstable telomeres (genomic damage) in the senescent phase of pre-cancers (i.e., adenoma, in situ pre-cancers) causing genomic errors, needed for telomerase re-activation. They stressed the importance of the telomerase-associated immortalization process as an oncogenic, cancer-deciding event, but poorly, cancer-research attended-to. In a model on this oncogenic transformation event, it was calculated that three mutations, were sufficient to instigate the cancer-important change [6]. Whereas, we suggested [20] that two mutations (e.g., p16ink4a and $\mathrm{Rb}$ ) occurring in accumulated, tetraploid 4n/4C/G1 cells in the senescent phase, could trigger S-period entry $(\mathrm{G} 1>\mathrm{S})$ with resultant cell cycling in the $3 n-4 n$ range [82] [83]. The absence of this type of $3 n-4 n$ cell cycling in the above immortalization, we suggest was precluded from the used methodology, perhaps specifically from shRNA, gene silencing. 


\section{Unicellular Origin of Self-Inflicted 4n Nuclear, $90^{\circ}$-Rotation}

Primitive fission yeast has been reported to undergo, $90^{\circ}$ self-inflicted nuclear re-orientation before division [94] [95] [96], which suggests that the performance in normal human cells is evolutionary conserved. But why is this extraordinary, phenomenon, specifically observed for $4 \mathrm{n}$ cells, having gone through a genome-repair induced MSP cell cycle? The answer is hidden in basal to apical cytoplasmic and nuclear differentiation of unicellular organisms [97], especially true for moving and exoskeleton differentiated organisms. In mammalian cells, cell/-nuclear division would be according to axial polarity of the cytoskeleton, which if followed for these unicellular organisms would be fatal. The nucleus in simple propagation has to turn $90^{\circ}$ to the axial differentiated conditions, before organismal division to two mirror halves. There are several today-living unicellular organisms undergoing such "perpendicular division-system", best described from Aulachan tha scoolimantha [98] [99], and note, the division-system was also amitotic, whole genome segregation. The similar occurrence in primitive yeast and in human cells is indeed evidence of evolutionary conservation of this primitive division-system [100]. But, why is the $90^{\circ}$ rotation occurring for 4 cells, derived from a DNA-damage-repair cell cycle?

Before meiosis evolution, genome damage repair has been suggested to involve doubling of the unicellular organism's genome [101] [102] [103]. The many evolutionary early/early developed differ-rent, DNA-repair, enzyme-systems [104], indicate archaic organism's “fight” for survival in genome-destabilizing environments. From a haploid organism's DNA-repair process, a doubling of the genome certainly makes sense, but any such type of doubling would demand evolved "genome reductive" processes for back-to vegetative, genome propagative constitutions. With the DNA damage occurring in pre-division, vegetative phase, the genome doubled nucleus would be in a differentiated basal-axial orientation. This of course as above, would demand a perpendicular reorientation of the $2 \mathrm{n}-4 \mathrm{n}$ nucleus before genome reductive division back to vegetative constitution. One wonderment however, is why this linkage between DNA-repair, nuclear perpendicularity and genome-reductive division has had metazoan, evolutionary selective advantage, all the way to the human genome? Even in highly evolutionary, specialized "end-point" animals, such as in Diptera, Drosophila larval cells responded to nutrition-deficiency induced genomic damage with "special" 4 n cells, undergoing amitotic, whole genome segregation, to diploid cells with "skewed" proliferation from progeny cells to cancer-like growth [105].

\section{Predictive Cellular Events from 4n-Skewed Division-System in 3-Dimensional Tissues}

In renewal tissues in which cancer originate, the $4 \mathrm{n}$-skewed division system can explain the occurrence of two basic types of cancer cell growths, the flat squam- 
ous and the basal "columnar" types. Thinking in terms of an $\mathrm{X}$ - Y $90^{\circ}$ angle, especially in three dimensional (3-D) tissue-structure, the nuclear perpendicularity to the cell cytoskeleton, polarity axis, can either be according to $\mathrm{X}$ or $\mathrm{Y}$, in other words along two different axial planes. In two studies, analyzing BE pre-cancers for mutational contributions to paired carcinomas, the pre-cancerous mutations were present in the carcinomas, and strangely, there were few new mutations acquired by the carcinomas [106] [107]. And, in the latter study both squamous and basal-cell (columnar) carcinomas, were observed. The authors suggested that the carcinomas originated, not from accumulated mutational changes, but from a "more direct path", involving epigenetic change and "genome doubling", succeeded by "oncogenic amplifications" [107]. Not only is the prediction of two types of cancer growth from the $4 \mathrm{n}$-skewed system fulfilled, but occurrence of this tetraploidy is hinted-at in early tumorigenesis. Another BE carcinoma sequencing analysis detected "recur-rent driver events", CAN-gene-mutations, which raises the question of how the $4 n$-skewed system can be the cause of these gene mutations (in prep.) [108].

\section{What Is Metaplasia? Claimed in Embryology and in Cancer Evolution}

The word metaplasia was coined by Virchow in the $1850^{\text {th }}$ and is a historic expression of the transition of one cell type into another in embryology, and similarly claimed to occur in cancer evolution. At that time it argued against the concept of "each cell from a cell like itself", eagerly debated [65]. This histologically baffling observation from "transition images" in embryology, descriptively also seen in cancer evolution became, metaplasia. This historic term is surviving today as such in cancer research, also with embryological-like events. In other words there are two existing terminologies for "one-same" cancer idea, which is powering the quick assertion of cancer evolution being "development gone awry" cited in numerous articles. This dangerous theory has no references to the fact that the Virchow-time, scientists in their debates of metaplasia from transition images concluded that: one cell type could be "replaced" by another, or a type of cell could respond to environmental change and be shape-changed (histological accommodation). Additionally, von Hansemann, as mentioned, from microscopy with camera facility, approached metaplasia (EMT/MET) from "the study of cell division", assuming "various advantages over mere contemplation of non-dividing cells" ([65], p. 188). He agreed with other colleagues that "epithelium can never form connective tissue and connective tissue can never form epithelium". He further argued against tumor cells having embryological cell functions, and saw metaplasia (EMT/MET) in tumor development being a route to increases in cell polarity-changes, causing advances in cell roundness shape, conferring tumor-autonomy existence. From his chromosome observations, he even speculated that metaplasia was connected to a genomic doubling process with multiple chromosome arms, which can mean diplochromosomes.

Having established that metaplasia and EMT/MET are one and the same con- 
cept for embryo-logical developmental processes in cancer evolution, the detailed cellular events revealed in pathological hyperplasia give clues about causative mechanism. The most frequently referred to example of one cell type changing into another, is in Barrett's esophagus (BE), where columnar cells replace the flat squamous cell epithelium [109] [110] [111]. But, there is confusion of whether: 1) intestinal columnar cells have transited through the gastroesophageal junction into the esophagus and displaced squamous epithelium, or 2) whether the presence of columnar cells in normal esophagus epithelium is derived from a metaplastic process. On the other hand, the agreements were that the "columnar" BE lesions showed signifycant increased risk of changing to oncogenic dysplasia with further carcinoma-development. Secondly, this BE occurrence was preceded by acid reflux disease, which caused genomic damaged cell-lesions in normal epithelium. Another interesting observation, hinting $4 \mathrm{n}$-skewed cell division from the lesion with chromosomal damage (acid caused), is that in BE hyperplasia pre-cancer lesions, $4 \mathrm{n}$-cells, cytometry isolated, in cell culture, were shown to cycle with reductive division back to shape-changed proliferative diploid cells [21] [81]. Other such pre-cancers have shown activated, genome-damage repair foci $(\gamma \mathrm{H} 2 \mathrm{AX})$ distributed over the genome with chromosome locations [112]. Rubin [113] from his "cancer-cell" studies of 3T3 and 10T1/2 cell lines, established from DNA-repair of starvation induced DNAdamage (AA deficiency, [44]), summarized his cancer-concept as: "Heritable, population-wide damage to cells as driving force of neoplastic transformation", to which we add: initial DNA-damage-repair of cells in the primary chromosome damaged cell lesion with causation of $4 \mathrm{n}$-skewed, amitotic, division-system to progeny cells with fitness-gained clonal expansions. The agreement with $\mathrm{Ru}-$ bin, is in heritability of the $4 \mathrm{n}$-skewed, amitotic, division-system (cycling in BE [81]) providing CIN and mutator mechanism for genetic/epigenetic variability in cancer evolution (in prep.) [19] [20] [21].

\section{4n-Skewed Cell Division Occur in Metaplasia-EMT/MET Cancer-Concepts}

Briefly, the consequences from the primitive, $4 \mathrm{n}$-skewed cell division-system were: 1) fitness-gain of genome reduced diploid cells, 2) loss/change of cell polarity in progeny cells, 3) re-building of the cytoskeleton, 4) destruction of adhesion protein E-cadherin- $\beta$-catenin complex, 5) cell-freedom from contact inhibition with gained mobility and proliferation, and 6) skewed/-perpendicular growth from these latter cells. Strangely, these 6 cellular occurrences appear to be similar to those claimed in tumorigenesis from embryological-like EMT/MET events [27] [66]. The goal in these ongoing, high-interest studies, centers on definitions of genes controlling EMT/MET in embryology, being biomarkers for therapy in tumorigenesis [21] [81] [114] [115] [116] [116]. For example, the EMT was described as phases with "rapid changes in cellular phenotypes", such as: "-epithelial cells down-modulate cell-cell adhesion structures, alter their polarity, reorganize their cytoskeleton, and become isolated, motile” [115]. Like- 
wise, "epithelial cells lose cell-cell junctions and baso-apical polarity", and acquire mobility [114]. These incredible, similar cellular happenings to the above 6 events with claim of being from embryological EMT, are difficult to accept as fortuitous. And rightly so, because a more recent article described EMT as: "a multistage process including, transient polyploidization", with note, " $8 \mathrm{C}$ " cells (tetraploid $4 \mathrm{n} / 8 \mathrm{C}$ cells), and the also claimed production of "small cells" [116]. The authors also mentioned down-regulation of $\mathrm{CDH1}$, the E-cadherin gene with "EMT-linkage" to small cell-motility. These 4n, cellular occurrences to small cells, claimed to be from EMT, and the other, above descriptions, are clearly evidential materials for $4 \mathrm{n} / 8 \mathrm{C}$-skewed division system to genome reduced smaller-sized diploid cells. This evaluation, seriously questions the reality of embryo-logical metaplasia/EMT/MET in cancer evolution.

\section{4n-Skewed System in Survival from Therapy Chemo-Agents}

Firstly, it should be recognized that cytotoxic agents can cause DNA-damage in cells [118]. Tumor initiating cells (TICs,), were questioned about ability to revert back to epithelial phenotype by MET, as a potential therapeutic event against metastasis [27]. A cytotoxic agent was used to stimulate transcription of the E-cadherin gene in the TIC cells, which activated PKA and loss of histone H3 lysine-methylation (H3K9), giving rise to MET. However, the potential for DNAdamaging effect from the cytotoxin was not considered, and no methylation of H3K9, has been shown to produce tetraploid 4-chromatid, "butterfly" chromosomes [119]. If the TIC-experiment had been followed by high resolution microscopy, there would have been likely observation of $4 \mathrm{n}$, diplochromosomal cells in agreement with " $8 \mathrm{C}$ " "MET" occurrence [116]. These latter survival data from chemo-agent-induced DNA-damage-repair, throws light on other "repair and survive or die" occurrences to relapse cells [120] [121] [122]. In general, chemo-agents that break DNA have probability of inducing DNA-repair to 4n, diplochromosomes the signature of $4 \mathrm{n}$-skewed division-system. Today however, tetraploidy is verified by "easy" cytometry, missing the realization of $4 \mathrm{n}$-skewed system, dividing to chemo-resistant diploid cells. This very visible $4 \mathrm{n}$-signature has been replication described from "substitute" nucleotide incorporations [56] [123] [124] [125], and illustrated in cancer occurrence [37] [126] [127] and, thoroughly discussed in cancer [128]. But, most importantly, a TIC-type experiment can be used to test potential chemo-agents, weeding-out those that activate the $4 \mathrm{n}$-skewed system, with pick of those, inducing apoptosis and/or necrosis. In cancer-therapy such a test-system would be invaluable, per-haps preventing origin of relapse cells (a reduction would also be significant). However, reality has shown that to change anything that has reached publication-acceptance, this sanction of approval, is literally impossible to change, meaning a wanted substitution of endoreplicated $4 \mathrm{n}$ cells by $4 \mathrm{n}$-skewed system in cancer evolution. A suggestion is to offer proof-findings for the $4 \mathrm{n}$-skewed division-system by $\mathrm{mi}$ croscopy as a PHD program, by simple use of our AA, DNA-damage-repair 
model. We guarantee from borrowed expression, "insights into origins and new directions for the treatment of cancer" [28].

\section{Mutation Theory versus 4n-Skewed Cell Division in Cancer Evolution}

Having come to the realization that chasing after embryological biomarker for "one cell type changing into another", is not a sound solution of the cancer-riddle (see above), the next question is MT-role (mutation theory) in this puzzle. No doubt, the ultimate basics for any cellular mechanism in tumorigenesis is mutational in nature. But to go from mutational data from cancer cells to determination of altered normal cell processes, is "putting the cart in front of the horse", and is shown by two of the original sequencing scientist retired from "more of the same" [8] [32]. Up to 2009, there were defined about "100,000 somatic mutations from cancer genomes", with predictions of: "Over the next few years several hundred million more will be revealed", which in the cancer-puzzle: "will provide us with a fine-grained picture of the evolutionary processes '----.' providing insights into origins and new directions for the treatment of cancer" [28]. Now, almost a decade later, perhaps, a billion known mutations, but with sequencing still going-on seen in governmental support for genome constitutional CAN-gene mutations [129] [130]. This incomprehensive pursuit has openly, been mentioned of being driven, sadly, by industrial and private greed (loss of ethics?) [24] [25].

The basics for this cancer-paradigm-loss [8], we see as an "over-focused" pursuit of CAN-gene mutation-identifications from cancers. Their all-importance is seen in the central situation they play in break-through immunotherapy treatments [24] [25], in which some 50 of them are being tested for antibody production, awaiting FDA, patient approval. This emphasis is also seen in the newly launched "Initiative"-program, identifying CAN-gene mutation as carrier-conditions from a million people for use in individual, cancer-risk calculations [129] [130]. The goal is development of therapy agents against their cancer activity. However, at this point a likely unwelcome truth is that we have forgotten that the traits conferred upon the CAN-gene, mountain mutations, in cancers [10] [23], were ideas, pure suggestions of cancer-causation, select-ability and tumor-driver capacity (see above quotes). This "slip of the mind" is today quite apparent in titles of reports, referring to these assumed traits as real [108] [131]. But, perhaps worse is the mentioned, solo importance of these mutations in the very promising cure-type immunotherapies [24] [25] [132]. (We contend that these gene-mutations, most likely are consequences in the $4 \mathrm{n}$-skewed, amitotic division system, in prep). Nevertheless, there should be awareness of that time-gone, changes suppositions into truisms, science not excluded, because our brains prefer positive assertiveness, and not wishy-washy uncertainties [75] [133]. This slip of the mind is a would-be serious problem in disease and therapy, and needs attention from counter measures. But remarkably, this mind-change 
was noted in science by Virchow $\left(1850^{\text {th }}\right)$, which he called the dogma-state: first supposition, then assertion, and then the faith to fanatics. However, the original suggestions of CAN-gene contributions to cancer evolution are of course, still valid, as such, and we agree that these mutations are: "causally involved in the neoplastic process". It is their route of origin, and their functions in tumorigenesis, which are the essential questions, now to be solved. Equally so, molecular scrutiny of the $4 \mathrm{n}$-skewed, amitotic division to "measureable" fitness-gained cells, is a "must-do". This, because of the herein presented evidences for chain-causative events for in vivo carcinoma occurrence from normal human cells [20] [21] [70] [71]. No doubt, there will be doors opened for resolutions to many issues in the cancer-riddle, not the least for more integrity in cure-type-results from the all-important immunotherapy approaches.

\section{Conclusion}

Previous publications and herein on special tetraploidy, self-inflicted nuclear $90^{\circ}$ reorientation, were concluded to be significant in cells, gaining diploid, proliferative freedom from contact inhibition, which is a normal state in renewal tissues where cancer originate. High resolution microscopy with chromosome details demonstrated this extraordinaire, type of tetraploidy, giving rise in vitro/in vivo, to fitness gained diploid cells (hyperplasia) from note, originally normal human cells. The hyperplasia in vivo culminated in pathological dysplasia and the carcinoma phenotype, which is a first-time achieved "chain of events" from initiation to full-blown cancer. The very first requirement in this chain, was DNADSBs in normal cells from which a type of repair-process, ongoing simultaneous with DNA-replication, led to MSP cycling to the peculiar, diplochromosomal tetraploidy. These $4 \mathrm{n}$ cells were peculiar, because they divided by amitosis, in absence of a spindle apparatus, and segregated firstly, whole genomes $(4 n / 8 \mathrm{C}>$ $4 \mathrm{n} / 4 \mathrm{C} / \mathrm{G} 1$ ) followed by reductive fission-division to fitness-gained diploid cells. These details allowed an assessment of origin of the self-inflicted $90^{\circ}$ turn, and its association to DNA-damage-repair, which could be traced to archaic unicellular organism's environmental stress-evolved propagative survival. This evolutionary conserved $4 \mathrm{n}$-mechanism in normal human cells, only need type-specific DNA-repair to be activated with expression of several skewed-division-consequences: 1) disrupted E-cadherin- $\beta$-catenin complex, 2) cytoskeleton new polarity construction in progeny cells, 3) cell proliferative liberty from contact inhibited tissues, 4) cell cycle time reduction of diploid cells, and 5) CIN and mutator mechanisms from inheritance of the $4 \mathrm{n}$-skewed system in progeny cells. It is time to acknowledge in cancer, DNA-DSB-repair, which through MSP triggers activation of human cell-conserved, primitive tetraploid reductive division-system. This unique $4 \mathrm{n}$-system, embodies the ultimate secret of cancer: a self-inflicted nuclear, perpendicular $/ 90^{\circ}$-orientation-change, relative to the cell polarity axis (cytoskeleton) before division to fitness-gained, progeny cells. Obviously, cell proliferation in this changed direction would for the whole population as a 
unit be "skewed" in placement relative to surrounding tissue. This very occurrence from the $4 \mathrm{n}$-system has been interpreted in cancers to derive from metaplasia/EMT/MET embryological developments with assumption of one cell type changing into another, but not yet with proven mechanism. The $4 \mathrm{n}$-skewed division system in this regard, is trumping the EMT/MET embryological concepts in cancer evolution from the inborn capacity of $90^{\circ}$ cell-division orientationchange with consequence of fitness-gained (hyperplasia) cells. Hence, the assumption of embryological EMT/MET in cancer evolution is wrong. This was actually shown by $8 \mathrm{C}(4 \mathrm{n})$ cells in a claimed MET event to "small cells" (4n, genome reduced diploid cells). Our goal of a chain-like causality of events for tumorigenic start from normal human cells has been fulfilled. The hope is that with one cancer clinic acknowledging DNA-damage-repair being cancer-linked that it will lead to "discovery" of the 4 n-skewed division-system.

\section{Acknowledgements}

Computer help greatly appreciated from Kathleen Olival.

\section{Conflicts of Interest}

The author declares no conflicts of interest regarding the publication of this paper.

\section{References}

[1] Ledford, H. (2010) The Cancer Genome Challenge. Nature, 464, 972-974. https://doi.org/10.1038/464972a

[2] Lengauer, C., Kinzler, K.W. and Vogelstein, B. (1998) Genetic Instability in Human Cancers. Nature, 396, 643-649. https://doi.org/10.1038/25292

[3] Nik-Zanail, S., Davies, H., Staff, J., Ramakrishna, M., Glodzik, D., Xou, X., Martincorena, I., et al. (2016) Landscape of Somatic Mutations in 560 Breast Cancer Whole Genome Sequences. Nature, 534, 47-54. https://doi.org/10.1038/nature17676

[4] Nowak, M.A. and Waclaw, B. (2017) Genes, Environment, and "Bad Luck". Science, 355, 1266-1267. https://doi.org/10.1126/science.aam9746

[5] Tomasetti, C., Vogelstein, B. and Parmigiani, G. (2013) Half or More of the Somatic Mutations in Cancers of Self-Renewing Tissues Originate Prior to Tumor Initiation. Proceedings of the National Academy of Sciences of the USA, 110, 1999-2004. https://doi.org/10.1073/pnas.1221068110

[6] Tomasetti, C., Marchionni, L., Nowak, M.A., Parmigiani, G. and Vogelstein, B. (2015) Only Three Driver Gene Mutations Are Required for the Development of Lung and Colorectal Cancers. Proceedings of the National Academy of Sciences of the USA, 112, 118-123. https://doi.org/10.1073/pnas.1421839112

[7] Tomasetti, C., Li, L. and Vogelstein, B. (2017) Stem Cell Divisions, Somatic Mutations, Cancer Etiology, and Cancer Prevention. Science, 355, 1330-1334. https://doi.org/10.1126/science.aaf9011

[8] Weinberg, R.A. (2014) Coming Full Circle-From Endless Complexity to Simplicity and Back Again. Cell, 157, 267-271. https://doi.org/10.1016/j.cell.2014.03.004

[9] Hanahan, D. and Weinberg, R.A. (2011) Hallmarks of Cancer: The Next Genera- 
tion. Cell, 144, 646-674. https://doi.org/10.1016/j.cell.2011.02.013

[10] Li, R., Sonik, A., Stindl, R., Rasnick, D. and Duesberg, P. (2000) Aneuploidy vs. Gene Mutation Hypothesis of Cancer: Recent Study Claims Mutation but Is Found to Support Aneuploidy. Proceedings of the National Academy of Sciences of the USA, 97, 3236-3241. https://doi.org/10.1073/pnas.97.7.3236

[11] Walen, K.W. and Stampfer, M.R. (1989) Chromosome Analyses of Human Mammary Epithelial Cells at Stages of Chemical-Induced Transformation Progression to Immortality. Cancer Genetics and Cytogenetics, 37, 249-261. https://doi.org/10.1016/0165-4608(89)90056-3

[12] Bozic, I., Antal, T., Ohtsuki, H., Carter, H., Kim, D., Chen, S., Karchin, R., et al. (2010) Accumulation of Driver and Passenger Mutations during Tumor Progression. Proceedings of the National Academy of Sciences of the USA, 107, 1854518550. https://doi.org/10.1073/pnas.1010978107

[13] Cairns, J. (1983) Cancer: Science and Society. W.H. Freeman \& Company.

[14] Kinzler, K.W., Nowak, M.A., Komarova, N.L., Sengupta, A., Jallepalli, P.V., Shih, le-M. and Vogelstein, B. (2002) The Role of Chromosomal Instability in Tumor Initiation. Proceedings of the National Academy of Sciences of the USA, 99, 1622616231. https://doi.org/10.1073/pnas.202617399

[15] Rubin, H. (1993) Epigenetic Nature of Neoplastic Transformation. In: Hodges, G.M. and Rowlett, Eds., Developmental Biology and Cancer, CRC Press, Ann Arbor.

[16] Holland, A.J. and Cleveland, D.W. (2012) Losing Balance: The Origin and Impact of Aneuploidy in Cancer. EMBO Reports, 13, 501-514.

https://doi.org/10.1038/embor.2012.55

[17] Sanghee, L. and Ganem, N.J. (2014) Tetraploidy and Tumor Development. Oncotarget, 5, 10959-10960.

[18] Sheltzer, J.M. and Amon, A. (2011) The Aneuploidy Paradox: Costs and Benefits of an Incorrect Karyotype. Trends in Genetics, 27, 446-453.

https://doi.org/10.1016/j.tig.2011.07.003

[19] Walen, K.H. (2012) Genome Reversion Process of Endopolyploidy Confers Chromosome Instability on the Descendent Diploid Cells. Cell Biology International, 36, 137-145. https://doi.org/10.1042/CBI20110052

[20] Walen, K.H. (2016) Cancer Prevention: Fundamental Genomic Alterations Are Present in Preneoplasia Including Function of High Frequency Selected Mutations (HFSM). Journal of Cancer Therapy, 7, 416-426. https://doi.org/10.4236/jct.2016.76044

[21] Walen, K. (2017) Mitotic Slippage Process Concealed Cancer-Sought Chromosome Instability Mechanism (S-CIN). Journal of Cancer Therapy, 8, 608-623. https://doi.org/10.4236/jct.2017.86052

[22] Weaver, B.A.A. and Cleveland, D.W. (2009) The Role of Aneuploidy in Promoting and Suppressing Tumors. The Journal of Cell Biology, 185, 935-937. https://doi.org/10.1083/jcb.200905098

[23] Wood, L.D., Parsons, D.W., Jones, S., Lin, J., Sjoblom, T., Leary, R.J., et al. (2007) The Genomic Landscapes of Human Breast and Colorectal Cancer. Science, 318, 1108-1113. https://doi.org/10.1126/science. 1145720

[24] Kelty, P.N. (2018) The Cancer Immunotherapy Revolution. Science, 359, 1345 1370 .

[25] Mueller, K.L. (2015) Realizing the Promise. Science, 348, 54-55. 
[26] Pattabiraman, D.R., Bierie, B., Kober, K.I., Thiru, P., Krall, J.A., Zill, C., Reinhardt, F., Tam, W.L. and Weinberg, R.A. (2016) Activation of PKA Leads to Mesenchymal-to-Epithelial Transition and Loss of Tumor-Initiating Ability. Science, 351, aad3680. https://doi.org/10.1126/science.aad3680

[27] Vogelstein, B., Papadopoulos, N., Velculescu, V.E., Zhou, S., Diaz Jr., L.A. and Kinzler, K.W. (2013) Cancer Genome Landscapes. Science, 339, 1546-1558. https://doi.org/10.1126/science.1235122

[28] Stratton, M.R., Campbell, P.J. and Futreal, P.A. (2009) The Cancer Genome. Nature, 458, 719-724. https://doi.org/10.1038/nature07943

[29] Loeb, L.A., Bielas, J.H., Beckman, R.A. and Bodmer, I.W. (2008) Cancers Exhibit a Mutator Phenotype: Clinical Implications. Cancer Research, 68, 3551-3557. https://doi.org/10.1158/0008-5472.CAN-07-5835

[30] Bodmere, W. and Loeb, L.A. (2008) Genetic Instability Is Not a Requirement for Tumor Development. Cancer Research, 68, 3558-3561. https://doi.org/10.1158/0008-5472.CAN-07-6544

[31] Vincent, M.D. (2010) The Animal Within: Carcinogenesis and Clonal Evolution of Cancer Cells Are Speciation Events Sensu Stricto. Evolution, 64, 1173-1183. https://doi.org/10.1111/j.1558-5646.2009.00942.x

[32] Kaiser, J. (2012) Cancer Genetics with an Edge. Science, 337, 282-284. https://doi.org/10.1126/science.337.6092.282

[33] Liu, J.K. (2014) Anti-Cancer Vaccines-A One Hit Wonder? Yale Journal of Biology and Medicine, 87, 481-489.

[34] Mitelman, F. (1988) Catalog of Chromosome Aberrations in Cancer. Alan Liss, Inc., New York.

[35] Heim, S. and Mitelman, F. (1995) Cancer Cytogenetics: Chromosomal and Molecular Genetic Aberrations of Tumor Cells. 2nd Edition, Wiley-Liss, Inc., New York.

[36] Mandahl, N., Johansson, B., Mertens, F. and Mitelman, F. (2012) Disease-Associated Patterns of Disomic Chromosomes in Hyperhaploid Neoplasms. Genes, Chromosomes and Cancer, 51, 536-544. https://doi.org/10.1002/gcc.21947

[37] Bayani, J., Paderova, J., Murphy, J., Rosen, B., Zielenska, M. and Squire, J.A. (2008) Distinct Patterns of Structural and Numerical Chromosomal Instability Characterize Sporadic Ovarian Cancer. Neoplasia, 10, 1057-1065.

https://doi.org/10.1593/neo.08584

[38] Fearon, E.R. and Vogelstein, B. (1990) A Genetic Model of Colorectal Tumorigenesis. Cell, 61, 759-767. https://doi.org/10.1016/0092-8674(90)90186-I

[39] Margolis, R.L. (2005) Tetraploidy and Tumor Development. Cancer Cell, 8, 353 354. https://doi.org/10.1016/j.ccr.2005.10.017

[40] Walen, K.H. (2006) Human Diploid Fibroblast Cells in Senescence: Cycling from Polyploidy to Mitotic Cells. In Vitro Cellular \& Developmental Biology-Animal, 42, 216-224. https://doi.org/10.1290/0603019.1

[41] Benn, P.A. (1976) Specific Chromosome Aberrations in Senescent Fibroblast Cell Lines Derived from Human Embryos. American Journal of Human Genetics, 28, 465-473.

[42] Davoli, T., Denchi, E.L. and de Lange, T. (2010) Persistent Telomere Damage Induces Bypass of Mitosis and Tetraploidy. Cell, 141, 81-93. https://doi.org/10.1016/j.cell.2010.01.031

[43] Brito, D. and Rieder, C.L. (2006) Mitotic Slippage in Humans Occurs via Cyclin B Destruction in the Presence of an Active Checkpoint. Current Biology, 16, 1194- 
1200. https://doi.org/10.1016/j.cub.2006.04.043

[44] Cantor, J.R. and Sabatini, D.M. (2012) Cancer Cell Metabolism: One Hallmark, Many Faces. Cancer Discovery, 2, 881-898. https://doi.org/10.1158/2159-8290.CD-12-0345

[45] Walen, K.H. (2007) Bipolar Genome Reductional Division of Human Near-Senescent, Polyploid Fibroblast Cells. Cancer Genetics and Cytogenetics, 173, 43-50. https://doi.org/10.1016/j.cancergencyto.2006.09.013

[46] Walen, K.H. (2007) Origin of Diplochromosomal Polyploidy in Near-Senescent Fibroblast Cultures: Telomeres and Chromosomal Stability (CIN). Cell Biology International, 31, 1447-1455. https://doi.org/10.1016/j.cellbi.2007.06.015

[47] Swanson, C.P. (1957) Cytology and Cytogenetics. Prentice-Hall, Englewood Cliffs, NJ.

[48] Zybina, E.V., Zybina, T.G., Bogdanova, M.S. and Stein, G.I. (2005) Whole-Genome Chromosome Distribution during Nuclear Fragmentation of Giant Cells of Microtus rossiaemeridionalis Studies by Use of Gonosomal Chromatin Arrangement. Cell Biology International, 29, 1066-1070. https://doi.org/10.1016/j.cellbi.2005.10.014

[49] Brenner, S., Branch, A., Meredith, S. and Berns, M.W. (1977) The Absence of Centrioles from Spindle Poles of Rat Kangaroo (PtK2) Cells Undergoing Meiotic-Like Reduction Division in Vitro. The Journal of Cell Biology, 72, 368-379. https://doi.org/10.1083/jcb.72.2.368

[50] Vitale, I. and Kroemer, G. (2017) Spontaneous DNA Damage Propels Tumorigenicity. Cell Research, 27, 720-721. https://doi.org/10.1038/cr.2017.43

[51] Argueso, J.L., Westmoreland, J., Mieczkowski, P.A., Gawel, M., Petes, T.D. and Resnick, M.A. (2008) Double-Strand Breaks Associated with Repetitive DNA Can Reshape the Genome. Proceedings of the National Academy of Sciences of the United States of America, 105, 11845-118450.

https://doi.org/10.1073/pnas.0804529105

[52] Stephens, P.J., Greenman, C.D., Fu, B., Yang, F., Bignell, G.R., Mudie, L.J., Pleasance, E.D., Lau, K.W., et al. (2011) Massive Genomic Rearrangement Acquired in a Single Catastrophic Event during Cancer Development. Cell, 144, 27-40. https://doi.org/10.1016/j.cell.2010.11.055

[53] Przybytkowski, E., Lenkiewicz, E., Barrett, M.T., Klein, K., Nabavi, S., Greenwood, C.M.T. and Basik, M. (2014) Chromosome-Breakage Genomic Instability and Chromothripsis in Breast Cancer. BMC Genomics, 15, 579-592. https://doi.org/10.1186/1471-2164-15-579

[54] Durkin, S.G. and Glover, T.W. (2007) Chromosome Fragile Sites. Annual Review of Genetics, 41, 169-192. https://doi.org/10.1146/annurev.genet.41.042007.165900

[55] Walen, K.H. (2002) The Origin of Transformed Cells: Studies of Spontaneous and Induced Cell Transformation in Cell Cultures from Marsupials, a Snail and Human Amniocytes. Cancer Genetics and Cytogenetics, 133, 45-54. https://doi.org/10.1016/S0165-4608(01)00572-6

[56] Walen, K.H. (1965) Spatial Relationships in the Replication of Chromosomal DNA. Genetics, 51, 915-929.

[57] Deem, A., Keszthelyl, A., Blackgrove, T., Vayl, A., Coffey, B., Mathur, R. and Chabes, A. (2011) Break-Induced Replication Is Highly Inaccurate. PLoS Biology, 9, e1000594. https://doi.org/10.1371/journal.pbio.1000594

[58] Unal, E., Heidinger-Pauli, J.M. and Koshland, D. (2007) DNA Double Strand Breaks Trigger Genome-Wide Sister-Chromatid Cohesion through Eco1 (Ctf7). Science, 
317, 245-248. https://doi.org/10.1126/science.1140637

[59] Uhlmann, F. (2009) A Matter of Choice: The Establishment of Sister Chromatid Cohesion. EMBO Reports, 10, 1095-1102. https://doi.org/10.1038/embor.2009.207

[60] Harris, H. (1995) The Cells of the Body: A History of Somatic Cell Genetics. Cold Spring Harbor Laboratory Press, Cold Spring Harbor.

[61] Sonnenschein, C. and Soto, A.M. (1999) The Society of Cells. BIOS Scientific Publishers Ltd., Oxford, UK.

[62] Sonnenschein, C. and Soto, A.M. (2013) The Aging of the 2000 and 2011 Hallmarks of Cancer Reviews: A Critique. Journal of Biosciences, 38, 651-663. https://doi.org/10.1007/s12038-013-9335-6

[63] Gumbiner, B.M. and Kim, N.-G. (2014) The Hippo-YAP Signaling Pathway and Contact Inhibition of Growth. Journal of Cell Science, 127, 709-717. https://doi.org/10.1242/jcs.140103

[64] Soto, A.M., Maffini, M.V. and Sonnenschein, C. (2008) Neoplasia as Development Gone Awry: The Role of Endocrine Disruptors. International Journal of Andrology, 31, 288-293. https://doi.org/10.1111/j.1365-2605.2007.00834.x

[65] Bignold, L.P., Coghlan, B.L.D. and Jersmann, H.P.A. (2007) David von Hansemann: Contributions to Oncology, Context, Comments, and Translations. Birkhauser Verlag, Basel, Switzerland.

[66] Kalluri, R. and Weinberg, R.A. (2009) The Basics of Epithelial-Mesenchymal Transition. Journal of Clinical Investigation, 119, 1420-1428. https://doi.org/10.1172/JCI39104

[67] Hirohashi, S. (1998) Inactivation of the E-Cadherin-Mediated Cell Adhesion System in Human Cancers. The American Journal of Pathology, 153, 333-339. https://doi.org/10.1016/S0002-9440(10)65575-7

[68] Saito, A., et al. (1999) Disruption of E-Cadherin-Mediated Cell Adhesion System in Gastric Cancers of Young Patients. Japanese Journal of Cancer Research, 90, 993-999. https://doi.org/10.1111/j.1349-7006.1999.tb00847.x

[69] Morales, C.P., Souza, R.F. and Spechler, S.J. (2002) Hallmarks of Cancer Progression in Barrett's Oesophagus. The Lancet, 360, 1587-1589.

https://doi.org/10.1016/S0140-6736(02)11569-8

[70] Dikovskaya, D., Schiffmann, D., Newton, I.P., Oakley, A., Kroboth, K., Sansom, O., et al. (2007) Loss of APC Induces Polyploidy as a Result of a Combination of Defects in Mitosis and Apoptosis. The Journal of Cell Biology, 176, 183-193. https://doi.org/10.1083/jcb.200610099

[71] Coldwell, C.M., Green, R.A. and Kapland, K.B. (2007) APC Mutation Lead to Cytokinetic Failures in Vitro and Tetraploid Genotypes in Min Mice. The Journal of Cell Biology, 178, 1109-1120. https://doi.org/10.1083/jcb.200703186

[72] Kim, N.-G., Koh, E., Chen, X. and Gumbiner, B.M. (2011) E-Cadherin Mediates Contact Inhibition of Proliferation through Hippo Signaling Pathway Components. Proceedings of the National Academy of Sciences of the United States, 108, 1193011935. https://doi.org/10.1073/pnas.1103345108

[73] Thiery, J.P. and Huang, R. (2005) Linking Epithelial-Mesenchymal Transition to the Well-Known Polarity Protein Par6. Developmental Cell, 8, 456-458. https://doi.org/10.1016/j.devcel.2005.03.002

[74] Streichan, S.J., Hoerner, C.R., Schneidt, T., Holzer, D. and Hufnagel, L. (2014) Spatial Constraints Control Cell Proliferation in Tissues. Proceedings of the National Academy of Sciences of the United States, 111, 5586-5591. 
https://doi.org/10.1073/pnas.1323016111

[75] Walen, K.H. (2011) Normal Human Cell Conversion to 3-D Cancer-Like Growth: Genome Damage, Endopolyploidy, Senescence Escape, and Cell Polarity Change/ Loss. Journal of Cancer Therapy, 2, 181-189. https://doi.org/10.4236/jct.2011.22023

[76] Walen, K.H. (2013) Senescence Arrest of Endopolyploid Cells Renders Senescence into One Mechanism for Positive Tumorigenesis. In: Hayat, M., ed., Tumor Dor mancy, Quiescence, and Senescence, Vol. 1, Springer, Dordrecht, 215-226. https://doi.org/10.1007/978-94-007-5958-9_18

[77] Ronnov-Jensen, L., Petersen, O.W. and Bissell, M.J. (1996) Cellular Changes Involved in Conversion of Normal to Malignant Breast: Importance of the Stromal Reaction. Physical Review, 76, 69-125.

[78] Saunders, W.S., Shuster, M., Huang, X., Gharaibe, B., Enyenihi, A.H., Petersen, J. and Gollin, S.M. (2000) Chromosomal Instability and Cytoskeleton Defects in Oral Cancer. Proceedings of the National Academy of Sciences of the United States, 97, 303-308. https://doi.org/10.1073/pnas.97.1.303

[79] Royer, C. and Lu, X. (2011) Epithelial Cell Polarity: A Major Gatekeeper against Cancer? Cell Death \& Differentiation, 18, 1470-1477.

https://doi.org/10.1038/cdd.2011.60

[80] Wodarz, A. and Näthke, I. (2007) Cell Polarity in Development and Cancer. Nature Cell Biology, 9, 1016-1024. https://doi.org/10.1038/ncb433

[81] Barrett, M.T., Pritchard, D., Palanca-Wessels, C., Anderson, J., Reid, B.J. and Rabinovitch, P.S. (2003) Molecular Phenotype of Spontaneously Arising 4N (G2-Tetraploid) Intermediates of Neoplastic Progression in Barrett's Esophagus. Cancer Research, 63, 4211-4217.

[82] Steinbeck, R.G. (2004) Dysplasia in View of the Cell Cycle. European Journal of Histochemistry, 48, 203-211.

[83] Davoli, T. and de Lange, T. (2012) Telomere-Driven Tetraploidization Occurs in Human Cells Undergoing Crisis and Promotes Transformation of Mouse Cells. Cancer Cell, 21, 765-776. https://doi.org/10.1016/j.ccr.2012.03.044

[84] Ceol, C.J., Pellman, D. and Zon, L.I. (2007) APC and Colon Cancer: Two Hits for One. Nature Medicine, 13, 1286-1287. https://doi.org/10.1038/nm1107-1286

[85] Aoki, K. and Taketo, M.M. (2007) Adenomatous Polyposis Coli (APC): A Multi-Functional Tumor Suppressor Gene. Journal of Cell Science, 120, 3327-3335. https://doi.org/10.1242/jcs.03485

[86] Chan, K.L., Palmai-Pallag, T., Ying, S. and Hickson, I.D. (2009) Replication Stress Induces Sister-Chromatid Bridging at Fragile Site Loci in Mitosis. Nature Cell Biology, 11, 753-760. https://doi.org/10.1038/ncb1882

[87] Strumnikov, A.V. (2010) One-Hit Wonders of Genomic Instability. Cell Division, 5, 15. https://doi.org/10.1186/1747-1028-5-15

[88] Gisselsson, D., Petterson, L., Hoglund, M., Heldenbla, M., Gorunova, L., Wiegant, J., Mertens, F., DalCin, P., Mitelman, F. and Mandahl, N. (2000) Chromosomal Breakage-Fusion-Bridge Events Cause Genetic Intratumor Heterogeneity. Proceedings of the National Academy of Sciences of the United States, 97, 5357-5362. https://doi.org/10.1073/pnas.090013497

[89] Blagosklonny, M.V. (2007) Cancer Stem Cell and Cancer Stemloids. Cancer Biology \& Therapy, 6, 1684-1690. https://doi.org/10.4161/cbt.6.11.5167

[90] Kendall, S.D., Linardi, C.M., Adam, S.J. and Counter, C.M. (2005) A Network of Genetic Events Sufficient to Convert Normal Human Cells to a Tumorigenic State. 
Cancer Research, 65, 9824-9828. https://doi.org/10.1158/0008-5472.CAN-05-1543

[91] Hahn, W.C., Counter, C.M., Lundberg, A.S., Beijersbergen, R.L., Brooks, M.W. and Weinberg, R.A. (1999) Creation of Human Tumor Cells with Defined Genetic Elements. Nature, 400, 464-468. https://doi.org/10.1038/22780

[92] Garbe, J.C., Vrba, L., Sputova, K., Fuchs, L., Novak, P., Brothman, A.R., Jackson, M., et al. (2014) Immortalization of Normal Human Mammary Epithelial Cell in Two Steps by Direct Targeting of Senescence Barriers Does Not Require Gross Genomic Alterations. Cell Cycle, 13, 3423-3435. https://doi.org/10.4161/15384101.2014.954456

[93] Lee, J.K., Garbe, J.C., Vrba, L., Mivano, M., Futscher, B.W., Stampfer, M.R. and LaBarge, M.A. (2015) Age and the Means of Bypassing Stasis Influence the Intrinsic Subtype of Immortalized Human Epithelial Cells. Frontiers in Cell and Developmental Biology, 3, 13. https://doi.org/10.3389/fcell.2015.00013

[94] Solari, A.J. (2002) Primitive Forms of Meiosis: The Possible Evolution of Meiosis. Biocell, 26, 1-13.

[95] Castagnetti, S., Oliferenko, S. and Nurse, P. (2010) Fission Yeast Cells Undergo Nuclear Division in the Absence of Spindle Microtubules. PLoS Biology, 8, e1000512. https://doi.org/10.1371/journal.pbio.1000512

[96] Walen, K.H. (2009) Spindle Apparatus Uncoupling in Endo-Tetraploid Asymmetric Division of Stem and Non-Stem Cells. Cell Cycle, 8, 3234-3237. https://doi.org/10.4161/cc.8.19.9570

[97] Hall, R.P. (1953) Protozoology. In: Prentice-Hall Animal Science Series. In: Steinbach, H.B., Ed., Prentice-Hall, Inc., New York.

[98] Raikov, I.B. (1994) The Diversity of Forms of Mitosis in Protozoa: A Comparative Review. European Journal of Protistology, 30, 253-269. https://doi.org/10.1016/S0932-4739(11)80072-6

[99] Grell, K.G. and Ruthmann, A. (1964) Uber die Karyologie des Radiolars Aulacantha scolymantha und Feinstruktur seiner Chromosomen. Chromosoma, 15, 185-211. https://doi.org/10.1007/BF00285729

[100] Niculescu, V. (2018) Carcinogenesis: Recent Insight in Protist Stem Cell Biology Lead to a Better Understanding of Atavistic Mechanisms Implied in Cancer Development. MOJ Tumor Research, 1, 18-29.

[101] Haig, D. (1993) Alternatives to Meiosis: The Unusual Genetics of Red Algae, Microsporidia, and Others. Journal of Theoretical Biology, 163, 15-31. https://doi.org/10.1006/jtbi.1993.1104

[102] Hurst, L.D. and Nurse, P. (1991) A Note on the Evolution of Meiosis. Journal of Theoretical Biology, 150, 561-565. https://doi.org/10.1016/S0022-5193(05)80447-3

[103] Kondrashov, A.S. (1994) The Asexual Ploidy Cycle and the Origin of Sex. Nature, 370, 213-216. https://doi.org/10.1038/370213a0

[104] Fernholm, A. (2015) DNA Repair-Providing Chemical Stability for Life. The Royal Swedish Academy of Sciences.

[105] Lucchetta, E.M. and Ohlstein, B. (2017) Amitosis of Polyploid Cells Regenerates Functional Stem Cells in Drosophila Intestine. Cell Stem Cell, 20, 609-620. https://doi.org/10.1016/j.stem.2017.02.012

[106] Agrawal, N., Jiao, Y., Bettegowda, C., Hutfless, S.M., Wang, Y., David, S., et al. (2012) Comparative Genomic Analysis of Esophageal Adenocarcinoma and Squamous Cell Carcinoma. Cancer Discovery, 2, 899-905.

https://doi.org/10.1158/2159-8290.CD-12-0189 
[107] Stachler, M.D., Tailor-Weiner, A., Peng, S., McKenna, A., Agoston, A.T., Odze, R.D., Davison, J.M., et al. (2015) Paired Exome Analysis of Barrett's Esophagus and Adenocarcinoma. Nature Genetics, 47, 1047-1055. https://doi.org/10.1038/ng.3343

[108] Dulak, A.M., et al. (2013) Exome and Whole Genome Sequencing of Esophageal Adeno-Carcinoma Identifies Recurrent Driver Events and Mutational Complexity. Nature Genetics, 45, 478-486. https://doi.org/10.1038/ng.2591

[109] Bhardwaj, A., Stairs, D.B., Mani, H. and McGarrity, T.J. (2012) Barrett's Esophagus: Emerging Knowledge and Management Strategies. Pathology Research International, 2012, Article ID: 814146. https://doi.org/10.1155/2012/814146

[110] Bignold, L.P. (2005) Embryonic Reversions and Lineage Infidelities in Tumor Cells: Genome-Based Models and Role of Genetic Instability. International Journal of $E_{X}$ perimental Pathology, 86, 67-79. https://doi.org/10.1111/j.0959-9673.2005.00421.x

[111] Wong, D.J., Paulson, T.G., Prevo, L.J., Galipeau, P.C., Longton, G., Blount, P.L., et al. (2001) p16 ${ }^{\mathrm{INK} 4 \mathrm{a}}$ Lesions Are Common, Early Abnormalities That Undergo Clonal Expansion in Barrett's Metaplastic Epithelium. Cancer Research, 61, 8284-8289.

[112] Gorgoulis, V.G., Vassillou, L.-V.F., Karakaldos, P., Zacharatos, P., Kotsinas, A., Liloglou, T., et al. (2005) Activation of the DNA Damage Checkpoint and Genomic Instability in Human Precancerous Lesions. Nature, 434, 907-912. https://doi.org/10.1038/nature03485

[113] Rubin, H., Yao, A. and Chow, M. (1995) Heritable, Population-Wide Damage to Cells as Driving Force of Neoplastic Transformation. Proceedings of the National Academy of Sciences of the United States of America, 92, 7734-7738. https://doi.org/10.1073/pnas.92.17.7734

[114] Talbot, L.J., Bhattacharya, S.D. and Kuo, P.C. (2012) Epithelial-Mesenchymal Transition, the Tumor Microenvironment, and Metastatic Behavior of Epithelial Malignancies. International Journal of Biochemistry and Molecular Biology, 3, 117-136.

[115] Klymkowsky, M.W. and Savagner, P. (2009) Epithelial-Mesenchymal Transition-A Cancer Researcher's Conceptual Friend and Foe. The American Journal of Pathology, 174, 1588-1593. https://doi.org/10.2353/ajpath.2009.080545

[116] Rohnalter, V., Roth, K., Finkernagel, F., Adhikary, T., Obert, J., Dorzweiler, K., et al. (2015) A Multi-Stage Process Including, Transient Polyploidization and EMT Precedes the Emergence of Chemoresistant Ovarian Carcinoma Cells with a Dedifferentiated and Pro-Inflammatory Secretory Phenotype. Oncotarget, 6, 40005-40025. https://doi.org/10.18632/oncotarget.5552

[117] Turajlic, S. and Swanton, C. (2016) Metastasis as an Evolutionary Process. Science, 352, 169-175. https://doi.org/10.1126/science.aaf2784

[118] White, E. and DiPaola, R.S. (2009) The Double-Edged Sword of Autophagy Modulation in Cancer. Clinical Cancer Research, 15, 5308-5316. https://doi.org/10.1158/1078-0432.CCR-07-5023

[119] Peters, A.H., O’Caroll, D., Scherthan, H., Mechtler, K., Sauer, S., Schofer, C., et al. (2001) Loss of Suv39h Histone Methylation Transcription in Mammalian Heterochromatin and Genome Instability. Cell, 107, 323-337.

https://doi.org/10.1016/S0092-8674(01)00542-6

[120] Puig, P.E., Guilly, M.N., Bouchot, A., Droin, N., Cathelin, D., Bouyer, F., et al. (2008) Tumor Cell Can Escape DNA-Damaging Cisplatin through DNA Endoreduplication and Reversible Polyploidy. Cell Biology International, 32, 2031-2043. https://doi.org/10.1016/j.cellbi.2008.04.021

[121] Wang, Q., Wu, P.C., Dong, D.Z., Ivanova, I., Chu, E., Zeliadi, S., Vesselle, H. and 
Wu, D.Y. (2013) Polyploidy Road to Therapy-Induced Cellular Senescence and Escape. International Journal of Cancer, 132, 1505-1515.

https://doi.org/10.1002/ijc.27810

[122] Mirzayans, R., Andrais, B., Kumar, P. and Murray, D. (2016) The Growing Complexity of Cancer Cell Response to DNA-Damaging Agents: Caspase 3 Mediates Cell Death or Survival? International Journal of Molecular Sciences, 17, 708. https://doi.org/10.3390/ijms17050708

[123] Schwarzacher, H.G. and Schnedl, W. (1966) Position of Labelled Chromatids in Diplochromosomes of Endo-Reduplicated Cells after Uptake of Tritiated Thymidine. Nature, 209, 107-108. https://doi.org/10.1038/209107a0

[124] Takanari, H., Nakakuki, K. and Izutsu, K. (1985) Cytogenetic Demonstration of Out-of-Phase DNA Synthesis in Endoreduplicated CHO Cells: Evidence for Partial Endoreduplication. Cytogenetics and Cell Genetics, 39, 93-98.

https://doi.org/10.1159/000132114

[125] Matsumoto, K. and Ohta, T. (1994) Chemical Induction of Quadruple and Octuple Chromosomes in Chinese Hamster CHO-K1 Cells and Relationship between Three-Dimensional Structure and Spatial Distribution of BrdU-Labeled Chromatids. Chromosoma, 103, 338-342. https://doi.org/10.1007/BF00417881

[126] Levan, A. and Hauschka, T.S. (1953) Endomitotic Reduplication Mechanisms in Ascites Tumors of the Mouse. Journal of the National Cancer Institute, 14, 1-43.

[127] Kuhn, E.M. (1981) A High Incidence of Mitotic Chiasma in Endoreduplicated Bloom's Syndrome. Human Genetics, 58, 417-421.

https://doi.org/10.1007/BF00282827

[128] Davoli, T. and de Lange, T. (2011) The Causes and Consequences of Polyploidy in Normal Development and Cancer. Annual Review of Cell and Developmental Biology, 27, 585-610. https://doi.org/10.1146/annurev-cellbio-092910-154234

[129] Collins, F.S. and Varmus, H. (2015) A New Initiative on Precision Medicine. The New England Journal of Medicine, 372, 793-795. https://doi.org/10.1056/NEJMp1500523

[130] Malkin, D., Garber, J.E., Strong, L.C. and Friend, S.H. (2016) The Cancer Predisposition Revolution: How Was the Inherited Basis of Cancer Foreshadowed? Science, 352, 1052-1053. https://doi.org/10.1126/science.aag0832

[131] Peifer, M., Fernandez-Cuesta, L., Sos, M.I., Geoge, J., Seidel, D., Kasper, L.H., Plenker, D., et al. (2012) Integrative Genome Analyses Identify Key Somatic Driver Mutations of Small-Cell Lung Cancer. Nature Genetics, 44, 1104-1112. https://doi.org/10.1038/ng.2396

[132] Cerwenka, A. and Lanier, L.L. (2016) Natural Killers Join the Fight Against Cancer. Science, 359, 1416-1417.

[133] Vosooughi, S., Roy, D. and Aral, S. (2018) The Spread of True and False News Online. Science, 359, 1146-1152. https://doi.org/10.1126/science.aap9559 